\title{
A POLÍTICA DE ASSISTÊNCIA ESTUDANTIL DO IFPE: CONHECENDO OS PROGRAMAS E A DEFINIÇÃO ORÇAMENTÁRIA NO CAMPUS PESQUEIRA
}

http://dx.doi.org/10.5902/2318133848536

\author{
Carlos Eduardo Correia Silva ${ }^{1}$ \\ Katharine Ninive Pinto Silva ${ }^{2}$
}

\begin{abstract}
Resumo
Este estudo foi realizado com o objetivo de abordar a política de assistência ao estudante do IFPE - campus Pesqueira. Tratou-se de uma pesquisa de campo e os procedimentos técnicos utilizados foram a pesquisa bibliográfica, a análise documental e a análise de conteúdo de entrevistas semiestruturadas. Os resultados obtidos pela demostraram que o IFPE - campus Pesqueira mantém programas e ações que envolvem os estudantes de todos os níveis de ensino da instituição, porém a redução no orçamento da Ação 2994 - Assistência ao educando da educação profissional afeta o potencial da política de assistência ao estudante.

Palavras-chave: assistência social; assistência estudantil; IFPE.
\end{abstract}

\section{IFPE'S STUDENT ASSISTANCE POLICY: KNOWING THE PROGRAMS AND THE BUDGET DEFINITION IN THE PESQUEIRA CAMPUS}

\begin{abstract}
This study was carried out in order to discuss IFPE's Student Assistance Policy. It was a field research, and the technical procedures used in this study were bibliographic research, document analysis and content analysis of semi-structured interviews. The results obtained by the research showed that the IFPE - campus Pesqueira develops programs and actions that involve students from all levels of education of the institution, however the reduction in the budget of the Action 2994 - Assistance to the student of professional education affects and a lot the potential of the student assistance policy.

Key-words: social assistance; student assistance; IFPE.
\end{abstract}

1 Instituto Federal de Pernambuco, Brasil. E-mail: cecdasilva.cc@gmail.com.

2 Universidade Federal de Pernambuco, Brasil. E-mail: katharineninive@gmail.com.

Regae: Rev. Gest. Aval. Educ. Santa Maria v. 10 n. 19 e48536, p. 1-16 2021 


\section{Introdução}

m 2010, pelo decreto n. 7.234, de 19 de julho, foi criado o Programa Nacional de Assistência Estudantil - Pnaes -, com o objetivo de ampliar as condições de permanência dos estudantes em instituições de ensino superior. Dessa forma como funcionaria a assistência estudantil nos institutos federais - instituições que oferecem, além do ensino superior, o ensino profissional nas modalidades integrado ao ensino médio; concomitante ou subsequente?

Os institutos federais de educação, ciência e tecnologia surgiram com a lei $n$. 11.892, pela qual se criou a rede federal de educação profissional, científica e tecnológica, vinculada ao Ministério da Educação. Além dos institutos a rede é formada pela Universidade Tecnológica Federal do Paraná, pelos centros federais de educação tecnológica Celso Suckow da Fonseca e o de Minas Gerais e pelas escolas técnicas vinculadas às universidades federais (Brasil, 2008). Os institutos federais são instituições singulares, pois abrangem diferentes níveis de ensino, do nível médio até a pósgraduação, além do estímulo à pesquisa e à extensão. Os institutos federais têm como finalidade desenvolver a educação profissional, mas sem deixar de lado a formação geral.

De acordo com Taufick (2014), apesar do questionamento sobre a funcionalidade do Pnaes para os estudantes de outro nível de ensino que não seja o superior, a criação deste programa conduziu a maioria dos institutos federais a um movimento de elaboração de uma política de assistência estudantil. $O$ autor chama atenção para o fato de que, apesar do Pnaes se referir aos alunos da educação superior, houve o incremento orçamentário, via Lei Orçamentária Anual - LOA -, da ação intitulada '2994 - Assistência ao educando da educação profissional', que disponibilizou recursos para que os institutos pudessem iniciar a sua política de assistência ao estudante. Diante disso, o Instituto Federal de Pernambuco - IFPE - apresentou política da assistência estudantil como

um instrumento que visa contribuir com o processo de criação, ampliação e consolidação de programas, projetos e ações que propiciem a permanência do estudante na Instituição, ou seja, é uma política que tem como finalidade prover os recursos necessários para o estudante superar os entraves do seu desempenho acadêmico, sendo, ainda, um instrumento de fortalecimento de uma formação voltada para o exercício da cidadania. (IFPE, 2012, p. 9)

Costa (2010) ressalta que, apesar desta política estar voltada prioritariamente para suprir a questão econômica do estudante de baixa renda, percebe-se um crescimento de ações que envolvem as áreas culturais, esportivas e psicológicas, como o Programa de Incentivo ao Esporte e Lazer, o Programa de Arte e Cultura e o Acompanhamento Biopsicossocial que são desenvolvidos dentro da política de assistência estudantil do IFPE, tornando a política de assistência mais ampla. Sendo assim, a assistência estudantil passou a atender tipos diferentes de pessoas com suas diferentes funções: social, pedagógica, psicológica.

Em Pernambuco a rede federal de educação profissional, científica e tecnológica é representada pelo Instituto Federal de Educação, Ciência e Tecnologia de Pernambuco IFPE - e pelo Instituto Federal do Sertão Pernambucano -IFSertão/PE. O IFPE é composto por dezesseis campi, sendo três oriundos do Centro Federal de Educação Tecnológica de Pernambuco: Ipojuca, Pesqueira e Recife; três provenientes das escolas 
agrotécnicas federais: Barreiros, Belo Jardim e Vitória de Santo Antão; três resultantes da segunda fase da política de expansão da rede federal: Afogados da Ingazeira, Caruaru e Garanhuns; e sete da terceira expansão: Cabo de Santo Agostinho, Palmares, Jaboatão, Olinda, Paulista, Abreu e Lima e Igarassu; além do campus Virtual da Educação a Distância.

Em Pesqueira, município do Agreste pernambucano, existe um campus do IFPE. Nesta unidade funcionam cursos de educação profissional técnica de nível médio, prioritariamente na forma de cursos integrados - Edificações e Eletrotécnica -, para os concluintes do ensino fundamental e para o público da educação de jovens e adultos, e cursos de formação inicial e continuada de trabalhadores. São ofertados cursos de nível superior: licenciatura em Matemática, licenciatura em Física, bacharelado em Enfermagem e bacharelado em Engenharia Elétrica.

De acordo com a lei n. 11.892 o IFPE deverá garantir o mínimo de $50 \%$ de suas vagas para atender à educação profissional técnica de nível médio, prioritariamente na forma de cursos integrados. No organograma do campus Pesqueira existe a Divisão de Assistência Estudantil - DAE -, que desenvolve vários programas voltados aos estudantes do campus, visando a contribuir para a igualdade de oportunidades e formação integral. Este setor é o responsável pelas ações da assistência estudantil.

O acesso ao ensino, como política educacional, não pode vir isolado. Tem que estar atrelado a uma política contra a evasão e a repetência, mas que não seja uma política preocupada apenas com números, mas sim, uma política que além de propiciar a permanência dos alunos na escola, busque elevar a qualidade da educação, pois manter o aluno no sistema de ensino nem sempre é o bastante para assegurar que o aprendizado aconteça. A Política de Assistência Estudantil do IFPE procura resolver parte desse problema, buscando reduzir os índices de evasão e retenção decorrentes de dificuldades de ordem socioeconômica.

Logo, pode-se dizer que o presente estudo tem sua contribuição ao trazer informações da política de assistência ao estudante do IFPE, fazendo um levantamento dos programas desenvolvidos no IFPE - campus Pesqueira, e ao revelar o processo de definição do orçamento para os diferentes programas da Política.

Para este estudo optou-se em desenvolver uma pesquisa qualitativa, se propondo a realizar uma compreensão própria e extensa do fenômeno social em questão. A pesquisa aconteceu no campus de Pesqueira do IFPE. A pesquisa teve a participação de seis sujeitos: foram entrevistados gestores, docentes e técnicos administrativos. Com relação aos procedimentos técnicos foram privilegiados a pesquisa bibliográfica, a análise documental e a entrevista semiestruturada. A realização da fase de coletas de dados foi orientada por dois procedimentos articulados: análise documental e entrevista semiestruturada. Foram utilizados nas análises quatro documentos referentes ao Instituto Federal de Educação, Ciência e Tecnologia de Pernambuco, a política de assistência ao estudante e seis entrevistas com sujeitos envolvidos na realização do Piel.

\section{A assistência estudantil para os alunos do ensino médio integrado dos institutos federais}

Com vista a garantir acesso, permanência e êxito para os estudantes foi criado o Pnaes, com os objetivos de democratizar as condições de permanência dos jovens na

\begin{tabular}{|l|l|l|l|l|r|}
\hline Regae: Rev. Gest. Aval. Educ. & Santa Maria & v. 10 & n. 19 & e48536, p. 1-16 & 2021
\end{tabular}


educação superior pública federal; minimizar os efeitos das desigualdades sociais e regionais na permanência e conclusão da educação superior; reduzir as taxas de retenção e evasão; contribuir para a promoção da inclusão social pela educação. A instituição do Pnaes trouxe, como consequência, a indução do movimento de elaboração da sua política de assistência estudantil. Houve o incremento orçamentário, via LOA, da ação intitulada '2994 - Assistência ao educando da educação profissional', que disponibilizou recursos para que os institutos pudessem implantar essa política, como pode ser observado no quadro abaixo.

Tabela 1 -

Execução orçamentária da ação 2994.

\begin{tabular}{c|c|c|c|c|c}
\hline LOA & $\begin{array}{c}\text { Dotação Inicial } \\
\mathrm{R} \$\end{array}$ & $\begin{array}{c}\text { Autorizado } \\
\mathrm{R} \$\end{array}$ & $\begin{array}{c}\text { Empenhado } \\
\mathrm{R} \$\end{array}$ & $\begin{array}{c}\text { Liquidado } \mathrm{R} \$ \\
\text { (Suplemento) }\end{array}$ & $\begin{array}{c}\text { Pago } \\
\mathrm{R} \$\end{array}$ \\
\hline 2009 & $22.712 .182,00$ & $23.6664 .984,00$ & $21.787 .423,11$ & $21.787 .423,11$ & $19.594 .391,18$ \\
\hline 2010 & $41.694 .449,00$ & $42.943 .938,00$ & $38.530 .840,48$ & $38.530 .840,48$ & $30.497 .703,11$ \\
\hline 2011 & $162.051 .472,00$ & $166.093 .263,00$ & $135.475 .654,90$ & $135.475 .654,90$ & $101.224 .792,41$ \\
\hline 2012 & $182.380 .329,00$ & $186.990 .689,00$ & $132.604 .513,36$ & $132.604 .513,36$ & $127.201 .944,23$ \\
\hline
\end{tabular}

Fonte: Taufick (2014).

Observa-se que logo após o decreto n. 7.234, em 2010, houve um aumento expressivo na dotação orçamentária da ação de assistência estudantil para as instituições federais de educação profissional. Neste decreto estão definidas as linhas de ação de assistência estudantil, as quais deverão ser desenvolvidas nas áreas de moradia estudantil; alimentação; transporte; atenção à saúde biopsicossocial; inclusão digital; cultura; desporto e lazer; creche; apoio didático-pedagógico; acesso, participação e aprendizagem de estudantes com deficiência, transtornos globais do desenvolvimento e altas habilidades e superdotação.

O Pnaes proporcionou um apoio não só ao social, mas também ao pedagógico e ao psicológico. Expandiu a percepção de assistência estudantil com a implantação de diferentes linhas de ação. Assim, os institutos federais passaram a formular suas políticas de assistência estudantil observando as diferentes linhas de ações apontadas no Pnaes, considerando como principal prioridade

viabilizar a igualdade de oportunidades e contribuir para a melhoria do desempenho acadêmico do aluno, além de agir, preventivamente, para minimizar as situações de repetência e evasão decorrentes da insuficiência de condições financeiras. (Fonaprace, 2012, p. 108)

Para que o estudante possa desenvolver-se em sua plenitude busca-se associar à qualidade do ensino à uma política efetiva de investimento em assistência, buscando "atender às necessidades básicas de moradia, de alimentação, de saúde, de esporte, de cultura, de lazer, de inclusão digital, de transporte, de apoio acadêmico e de outras condições" (Fonaprace, 2007 apud Fonaprace, 2012, p. 162). 


\section{Política de assistência estudantil do Instituto Federal de Educação, Ciência e Tecnologia de Pernambuco}

Segundo Oliveira e Duarte (2010), ao mesmo tempo em que se desenvolvem políticas educacionais universais há, também, o incremento de políticas educacionais focalizadas, que se concentraram em processos que asseguram 0 acesso e a permanência de grupos socialmente mais vulneráveis à escola.

A política de assistência estudantil é um exemplo de uma política educacional focalizada e tem o objetivo de efetuar ações que minimizem as necessidades socioeconômicas e pedagógicas e ajudar a efetivar a formação integral dos estudantes. A política de assistência estudantil do IFPE busca, pela assistência, garantir aos discentes condições materiais consideradas como imprescindíveis para a realização dos demais direitos, reprimindo a vulnerabilidade social (IFPE, 2012).

A política da assistência estudantil do IFPE se apresenta como um instrumento que visa a contribuir para a permanência do estudante na instituição: "É uma política institucional integrada ao processo educativo e a serviço da coletividade" (IFPE, 2012, p. 12). Uma política que, além de disponibilizar recursos para o estudante melhorar seu desempenho acadêmico, age como um instrumento de formação integral e cidadã. De acordo com o documento em questão, a política de assistência do IFPE busca a "ampliar as condições de permanência dos estudantes do IFPE, contribuindo para a igualdade de oportunidades no exercício das atividades acadêmicas, científicas, esportivas e culturais" (IFPE, 2012, p. 11).

O IFPE delimita a política de assistência estudantil no PDI como mais um instrumento a ser desenvolvido junto aos alunos, com o intuito de assegurar o caráter público e gratuito da instituição, trabalhar a inclusão educacional e social, pautada na igualdade de condições, para acesso e permanência com êxito do estudante no seu percurso educacional; atender o educando, respeitando aspectos socioeconômicos, culturais, étnicos e ambientais; trabalhar a convivência, com base no respeito e na solidariedade, observando preceitos éticos; preparar o estudante para intervir de forma consciente, crítica e criativa na sociedade, respeitando as diversidades culturais, as diferenças individuais e coletivas, como agente de formação e de transformação dessa mesma sociedade; vincular a educação ao trabalho e às práticas sociais; desenvolver a educação como pleno desenvolvimento da pessoa para o exercício da cidadania e sua qualificação para o trabalho (Brasil, 2015, p. 193).

A política de assistência estudantil do IFPE compreende o desenvolvimento de programas técnico-científicos, que contemplam as áreas estratégicas de ensino, pesquisa e extensão, e os programas específicos e universais. E tem como objetivos: assegurar o caráter público e gratuito da instituição, trabalhar a inclusão educacional e social, pautada na igualdade de condições, para acesso e permanência com êxito do estudante no seu percurso educacional; atender o educando, respeitando aspectos socioeconômicos, culturais, étnicos e ambientais; trabalhar a convivência, com base no respeito e na solidariedade, observando preceitos éticos; preparar o estudante para intervir de forma consciente, crítica e criativa na sociedade, respeitando as diversidades culturais, as 
diferenças individuais e coletivas, como agente de formação e de transformação dessa mesma sociedade; vincular a educação ao trabalho e às práticas sociais; desenvolver a educação como pleno desenvolvimento da pessoa para o exercício da cidadania e sua qualificação para o trabalho (IFPE, 2012, p. 9).

Esta política envolve os estudantes matriculados nos cursos e modalidades presenciais de ensino. $O$ atendimento pela política é prioritário aos estudantes advindos de escolas públicas ou com renda familiar per capita de até um salário mínimo e meio. Tem prioridade também os estudantes em situação de vulnerabilidade social, estudantes com deficiência, transtornos globais do desenvolvimento e altas habilidades e superdotação (IFPE, 2012).

A proposta do IFPE estabelece algumas diretrizes gerais para o desenvolvimento da política de assistência ao estudante na instituição: atendimento às necessidades socioeconômicas, culturais e pedagógicas dos estudantes; ampla divulgação dos benefícios, serviços, programas e projetos da assistência estudantil, bem como dos recursos oferecidos pela instituição e dos critérios para seu acesso; descentralização das ações da assistência estudantil desenvolvidas no IFPE, respeitando-se a autonomia dos campi; estímulo à participação de todos os segmentos da comunidade acadêmica do IFPE, no que diz respeito às questões relativas à assistência estudantil, nos espaços deliberativos deste instituto (IFPE, 2012, p. 10).

Percebe-se que a política de assistência pretende não se resumir à oferta de auxílio financeiro para os estudantes de baixa renda. É uma política mais extensiva, que busca atender, também, às necessidades culturais e pedagógicas dos estudantes. Orienta para uma ampla divulgação das atividades promovidas pela política de assistência, assim como os recursos oferecidos e as normas para o acesso do estudante. No tópico três afirma-se a autonomia de todos os campi em elaborar suas ações da assistência estudantil, de acordo com suas necessidades institucionais e os recursos orçamentários disponíveis. No IFPE a política de assistência ao estudante é viabilizada pela Diretoria de Assistência Estudantil - DAE/Reitoria -, em conjunto com as coordenações de assistência estudantil dos campi. Fazem parte da coordenação o chefe desse setor e a equipe multiprofissional. A DAE,

em conjunto com as coordenações de assistência estudantil dos campi ou instâncias equivalentes, deverá conduzir o processo de elaboração, implementação, acompanhamento e avaliação desta Política. Nesse processo, ressaltamos a importância da DAE, enquanto órgão gestor e articulador das ações a serem desenvolvidas no âmbito da Política de Assistência Estudantil. (IFPE, 2012, p. 12)

De acordo com a política de assistência estudantil do IFPE a equipe multiprofissional que faz parte das coordenações de assistência estudantil dos campi será constituída de assistente social, pedagogo, psicólogo, dentre outros profissionais, que de acordo com a sua competência exercerá suas aptidões relativas aos programas que fazem esta política (IFPE, 2012). As atribuições desta equipe são

planejar, implementar, acompanhar e avaliar a Política de Assistência; Divulgar as ações da assistência estudantil na perspectiva de consolidá-la como política institucional; Manter atualizado o cadastro dos estudantes 
atendidos pelos Programas de Assistência Estudantil; Acompanhar os recursos financeiros da rubrica de assistência ao educando; Elaborar anualmente relatórios dos Programas implementados através desta política e Articular os setores comprometidos com a exequibilidade da política de assistência estudantil nos campi. (IFPE, 2012, p. 13)

Os relatórios anuais deverão ser apresentados pela equipe multiprofissional dos campi à DAE/Reitoria. Sua entrega tem como objetivo fortalecer as ações já existentes ou redefinir estratégias de ação, com o intuito de garantir os objetivos da política da assistência estudantil na instituição (IFPE, 2012).

A política de assistência estudantil do IFPE compreende o desenvolvimento de programas técnico-científicos e os programas específicos e universais. Os programas técnicos-científicos buscam contribuir "para a formação intelectual, acadêmica e profissional dos estudantes" (IFPE, 2012, p. 15). Nesse grupo podem ser citados os Programas como o Pibic, Pibex, Monitoria, bolsa de incentivo acadêmico, dentre outros.

No grupo dos programas específicos fazem parte ações relacionadas com a manutenção acadêmica, auxílio financeiro, benefício eventual, apoio à participação em eventos, apoio a visitas técnicas e assistência ao estudante do Proeja. Esses programas visam ao "atendimento prioritário de estudantes que se encontram em situação de vulnerabilidade social e estudantes com deficiência, transtornos globais do desenvolvimento e altas habilidades e superdotação" (IFPE, 2012, p. 16).

Os programas universais se destinam a todos os estudantes regularmente matriculados em cursos presenciais do campus. Fazem parte deste grupo os programas de acompanhamento biopsicossocial, incentivo à cultura e arte, incentivo ao esporte e lazer. Apesar de abranger todos os estudantes, são considerados para a concessão da ajuda financeira os critérios de vulnerabilidade social e de necessidades educacionais específicas, os quais são identificados por meio de análise socioeconômica.

\section{Concepções dos sujeitos entrevistados sobre políticas sociais e assistência estudantil}

Em 2010, pelo decreto n. 7.234, de 19 de julho, foi criado o Pnaes. De acordo com os entrevistados a assistência estudantil antes do Pnaes existia, mas não existia uma organização voltada para a assistência ao estudante, o que havia eram alguns programas com pouca amplitude dentro do campus, atendendo poucos discentes.

Na realidade, praticamente não existia, você não tinha, por exemplo, como eu já fui estudante daqui, você precisava de uma viagem, o professor dizia: olha vamos ter que ir para Paulo Afonso, falando como ex-aluno, o ônibus vai custar $x$, o rateio entre os estudantes e os pais é que custearia essa viagem [...]. [...] você ir daqui a Belo Jardim pra fazer, olhar, aprender alguma coisa diferente na escola de lá, ir pra um congresso, alguma coisa, você não ia, você não tinha. Então após o Pnaes, onde foi liberada a questão da assistência ao estudante, aí sim, houve uma melhoria e daí os alunos conseguiram (ter assistência). (Entrevistado-01)

(O Pnaes) Traz para o Instituto, de uma maneira formal, já que existe um decreto, atividades que sempre foram feitas. Eu fui monitor na faculdade, mas não tinha esse processo já estabelecido, então eu trabalhei como 
monitor de graça, eu mesmo precisava do auxílio e não tive. Teria me facilitado muito, adquirido livros, materiais para estudos, pagar minhas passagens. (Entrevistado-02)

Tinha bolsa permanência, salvo engano, já havia a bolsa permanência, mas era como se fosse uma amostragem, alguns alunos, hoje nós temos uma amostragem dos que não se inserem. Tinha, me parece que, alguma coisa na área de pesquisa, não sei se algum programa na área de extensão, mas era algumas coisas fortuitas, que aparecia um programa ou outro como se fosse uma amostragem mesmo. (Entrevistado-04)

Segundo o entrevistado-06 o valor recebido para essa finalidade era muito pequeno, inviabilizando a criação de programas:

Era uma coisa extremamente precária, a gente tinha um recurso mínimo que era destinado aos campi [...], então esse recurso, claro que não dava pra gente criar esse tipo de programa, a gente utilizava ele para questões única e exclusivamente de benefícios eventuais [...], coisas muito, muito essenciais e básicas para que o estudante pudesse desenvolver as suas atividades didático- pedagógicas. (entrevistado-06)

O entrevistado cita a compra de óculos ou de próteses dentárias como alguns dos benefícios eventuais concedidos aos alunos. O mesmo entrevistado lembra que após a publicação do Pnaes surgiram vários programas, graças ao aumento de recursos para essa ação:

Depois do Pnaes eu acho que a gente com esse incentivo, começou com os programas aluno colaborador, com os programas de bolsa atleta (hoje $o$ Piel), bolsa de arte e cultura, programa de cerimonial e eventos, nós tivemos também a oportunidade de consolidar os programas de bolsas de monitoria, as bolsas do clube de astronomia, clube de matemática, então foram ações que se tornaram possíveis devido aos recursos mais volumosos com as ações prioritárias do Pnaes. (entrevistado-06)

Os campi agrícolas passaram a fazer parte dos institutos federais com a lei $n$. 11.892/08, que instituiu a rede federal de educação profissional, científica e tecnológica. Nestes campi já existia uma política de assistência ao estudante pelo fato do aluno estudar num regime de semi-internato ou internato, mas não era uma assistência com pagamento de auxílio financeiro. Segundo o entrevistado-06 era uma assistência que disponibilizava uma estrutura para que o aluno pudesse estudar nos regimes citados:

Os campi agrícolas quando se juntaram em termo de institutos no final de 2008, eles já tinham alguns tipos de incentivo, de desenvolvimento de esportes, por exemplo, que é necessário. Então você imagina um aluno que mora na instituição, você tinha que fazer alguma coisa pra ele passar o tempo, então eles já tinham algum tipo de incentivo, mas que não era um incentivo financeiro, era mais um incentivo de que? Você dar uma alimentação adicional, você dar também ao professor uma carga horária reservada para que ele desenvolvesse um programa de esportes e lazer, montava-se academia nos campi, a exemplo do Campus Belo Jardim, 
então, tinha um material esportivo adicional para que os alunos pudessem jogar suas peladas (futebol), fazer seus treinos de atletismo, essas questões para que eles pudessem passar o tempo, já que praticamente eles moram na instituição. (Entrevistado-06)

Apesar do Pnaes só citar os estudantes da graduação como beneficiários desta política, no campus Pesqueira a maioria dos recursos eram destinados aos estudantes do nível médio, até pelo fato de haver poucos estudantes do curso superior no campus naquele momento:

Na nossa cultura de ensino superior, até alguns anos atrás, até pouco tempo atrás, ela se resumia ao campus Recife, com cursos superiores de tecnologia, e aí foi se consolidando, criando cursos superiores no Instituto, de uma forma mais volumosa, digamos assim, de 2009 pra cá. Então o recurso da assistência ao educando, ele foi utilizado, acredito que $80 \%$, eu não tenho esse número exato, mas grande parte desse recurso no ensino técnico de nível médio. (Entrevistado-06)

De acordo com o entrevistado-01 não existe um direcionamento para um determinado nível de ensino, na verdade, tudo vai depender da demanda dos professores e gestores no início do ano letivo. O entrevistado-02 acredita que o Pnaes contribuiu para a autonomia do estudante, para a melhoria de sua autoestima:

A gente acha que é um valor pequeno, os meninos recebem $R \$ 180, R \$$ $200, R \$ 350,00$, mas para eles aquilo é muito representativo, faz muita diferença em ter a liberdade de poder comprar do seu próprio bolso, de um trabalho que eles estão realizando, um livro para seu próprio aperfeiçoamento, então isso é fundamental. (entrevistado-02)

A concepção dos entrevistados sobre o Pnaes é de que ele é muito importante, pois dá condições para que o aluno desenvolva melhor seus estudos. Um deles chega a colocá-lo como um "marco na história do Brasil".

O entrevistado-05 reafirma a importância do Pnaes, mas alerta que o mesmo já precisa de uma reformulação. Em 2020 o Pnaes completou dez anos e a proposta da política de assistência estudantil do IFPE oito anos. Note-se que no IFPE já se iniciou o processo para elaboração de uma nova proposta de política de assistência estudantil. Em 2018 a DAE/Reitoria realizou o Fórum de Assistência ao Estudante para discussão da nova política de assistência ao estudante do IFPE. Em 2020, por meio de formulário eletrônico, a proposta depolítica de assistência estudantil do IFPE foi apresentada para consulta pública.

Para o entrevistado-01 um dos principais benefícios trazidos pelo Pnaes é sua contribuição para a frequência e permanência do estudante no campus. Com isso o índice de reprovação e evasão tende a cair. Para ele existe uma relação entre o Pnaes e a permanência e o êxito do estudante no campus e quanto maior o aporte financeiro para desenvolver os programas de assistência, menor serão a evasão e a reprovação: "Eu acredito que sem ele (Pnaes), o índice de reprovação, de abandono, seria maior, por não ter, pelo menos, uma ajuda de custo para vir" (entrevistado-01).

O entrevistado-06 cita situações que podem aparecer no dia a dia do estudante que não recebe uma assistência por parte da instituição: 
Se você não mantêm o estudante na escola com algum tipo de apoio socioeconômico, com algum tipo de apoio financeiro, você vai fazer com que o estudante, ou precise ajudar em casa pra que o pai dele possa conseguir um trabalho ou um "bico", ou então ele mesmo vai ter que arrumar um emprego, mesmo sendo um aluno de menor (idade), mas ele vai ter que conseguir uma 'viração' como a gente diz né, pra complementar a renda familiar, então termina prejudicando bastante na permanência do estudante no curso. (entrevistado-06)

O entrevistado-02 espera que o Pnaes consiga ajudar mais ainda na formação integral do estudante com seus diferentes tipos de programas:

A minha opinião é que ela [a política de Assistência Estudantil] venha materializar esse esforço e fazer com que o estudante, ele se envolva, não só com as atividades acadêmicas regulares, mas com atividades esportivas que trazem aí perspectiva de competividade, de respeito, de trabalho em equipe, isso é muito importante também, pra que ele consiga se desenvolver de uma forma mais integral e se apegue mais ao processo educativo, não só aquela atividade meramente em sala de aula, o professor ensina o aluno aprende, é o que acontece em boa parte dos casos. (entrevistado-02)

A relação do Pnaes com a instituição é bem avaliada. É uma política que não se restringe a oferecer um auxílio financeiro, mas uma política que evoluiu bastante a noção de assistência e hoje envolve ensino, pesquisa e extensão para estudantes dos diferentes níveis de ensino do IFPE:

A política ela tem sido executada de uma forma, eu acredito que, muito eficiente, produtiva e necessária. A gente tem ampliado muito a questão da assistência estudantil, agora mesmo, recentemente, a gente mandou vários estudantes para um congresso no Acre, por exemplo, então esses estudantes, muitos deles nunca saíram dos seus Campi no interior e tiveram oportunidade de apresentar trabalhos de pesquisa em outro estado, viajar de avião [...], nós tivemos a oportunidade de mandar estudantes para o fórum mundial em Santa Catarina no ano de 2014, a gente teve a oportunidade de mandar, também, estudantes para o exterior, para participar de programas dentro das relações internacionais do Instituto, então são apenas alguns exemplos, mas a coisa, ela tomou uma dimensão que ela envolve ensino, pesquisa e extensão, um aporte financeiro para participação de eventos, para o desenvolvimento de práticas pedagógicas. (Entrevistado-06)

Porém, de acordo com o entrevistado-01, levando em consideração os valores pagos nas Universidades Federais, constata-se que os estudantes do IFPE, especificamente da graduação, poderiam ser contemplados com os mesmos valores, pois são do mesmo nível de ensino.

O entrevistado-05 concorda que a relação entre o Pnaes e o IFPE poderia melhorar. A sua principal crítica é sobre o orçamento que não permite contemplar todos os estudantes que realmente necessitam dessa política. Atualmente, por exemplo, devido aos cortes orçamentários, o orçamento da assistência estudantil teve uma redução e, por 
conta disso, programas sofreram diminuição no valor e no quantitativo dos auxílios, outros estão acontecendo sem a oferta de auxílios financeiros e os editais de alguns programas foram modificados não permitindo o acúmulo de auxílios financeiros de diferentes programas.

\section{Programas da assistência estudantil no IFPE - campus Pesqueira e a definição orçamentária}

A proposta da política de assistência ao estudante do IFPE apresenta os programas e ações que podem ser desenvolvidos nos campi. A política de assistência estudantil é conduzida pela DAE/Reitoria, em conjunto com as coordenações de assistência estudantil dos campi (IFPE, 2012).

Nas coordenações de assistência estudantil dos campi existe a equipe multiprofissional, que tem papel importante dentro da política de assistência. É ela quem coordena as ações e os programas nos campi. Porém, todo o trabalho desenvolvido pela equipe multiprofissional da Coordenação de Assistência ao Estudante - campus Pesqueira depende do orçamento liberado para execução das ações. Cada campus do IFPE recebe um valor anual para desenvolver os diferentes programas da política de assistência estudantil.

Seguindo as orientações da política de assistência estudantil do IFPE (IFPE, 2012), o ponto de partida para o planejamento das ações da assistência ao estudante é o perfil socioeconômico dos discentes. O estudante, ao fazer sua primeira matrícula, preenche um questionário socioeconômico, elaborado pelo serviço social, que servirá de base para a equipe formada por assistente social, psicólogo e pedagogo, junto com a equipe gestora do campus, planejar as ações a serem desenvolvidas no ano letivo.

Os três diferentes programas desenvolvidos pela política de assistência estudantil: técnico-científicos, pesquisa e extensão; específicos e universais reforçam alguns princípios desta política que são, principalmente, a inclusão social, melhoria do desempenho acadêmico e qualidade de vida. Tem como uma das estratégias pela permanência e pelo desempenho acadêmico o oferecimento de benefício financeiro ou estágios remunerados (IFPE, 2012).

Nos anos de 2018 e 2019 o campus Pesqueira ofereceu quase todos os programas apresentados na política de assistência ao estudante do IFPE. Nos técnicos-científicos foram desenvolvidos o Pibic, Pibex, Monitoria e BIA. Alguns sem o auxílio financeiro ou utilizando verba de outros orçamentos para complementar o pagamento dos auxílios.

No grupo dos programas específicos, nos anos de 2018 e 2019, o campus ofereceu os programas manutenção acadêmica, auxílio financeiro, benefício eventual, apoio à participação em eventos, apoio a visitas técnicas e assistência ao estudante do Proeja.

Já nos universais o único programa ofertado com pagamento de auxílio financeiro foi o de incentivo à cultura e arte. O outro programa deste grupo, o Programa de Incentivo ao Esporte e Lazer - Piel -, se desenvolve em duas linhas de ação. Na primeira oferece benefício financeiro que propicie as condições necessárias, para que os estudantes se dediquem ao treinamento esportivo e possam participar de competições nos âmbitos municipal, estadual, nacional e internacional. Pela segunda linha de ação se oferece 
benefício financeiro que propicie as condições necessárias para que os estudantes participem de atividades de esporte e lazer fora das dependências do campus (IFPE, 2012). Nos anos de 2018 e 2019, o IFPE - campus Pesqueira ofertou benefício apenas na linha de ação 2 deste programa.

A linha de 'ação 1 do Piel' não foi contemplada a receber recursos financeiros para a oferta de auxílios. Algumas atividades esportivas continuaram a ser ofertadas com o objetivo de formar e preparar equipes para a participação dos eventos esportivos. Diante da não oferta dos auxílios percebeu-se que o período de realização de algumas modalidades esportivas diminuiu: uma modalidade que oferecia treinos num período de sete meses durante $o$ ano, teve a duração de apenas 3 três meses.

De acordo com os relatórios de gestão (IFPE, 2018), após vários aumentos dos recursos financeiros disponibilizados para a ação '2994 - Assistência ao Estudante da Educação Profissional e Tecnológica' entre os anos de 2013 a 2015, o ano de 2016 apresentou um orçamento praticamente igual ao do ano anterior. Se em 2015 o orçamento foi de $R \$ 16.918,151$, para 2016 o IFPE teria um pouco menos que isso, $R \$$ $16.910,751$, para distribuir entre os campi visando a atender às demandas surgidas pelas ações desenvolvidas dentro da política de assistência estudantil

Segundo o entrevistado-06, no IFPE - campus Pesqueira, desde a implantação do Pnaes o orçamento da assistência estudantil teve um aumento muito significante. Algo que girava em torno de $R \$ 40.000$, em 2009, passou para $R \$ 1.748 .402,70$ em 2015. Deste valor noventa e nove por cento (99\%) foi executado, o equivalente a $R \$$ 1.737.526,40. Sendo assim, $R \$ 19.489,30$ foram devolvidos à Diretoria de Assistência Estudantil da Reitoria do IFPE.

De acordo com a planilha financeira apresentada pelo campus, em 2016 o orçamento da assistência estudantil praticamente não teve alteração: o campus recebeu $\mathrm{R} \$ 1.785 .922,00$ para a execução de programas e ações. Já em 2018 esse orçamento recebeu, aproximadamente, $\mathrm{R} \$ 950.000,00$. Em 2019 o orçamento foi de $\mathrm{R} \$ 984.451,21$, ou seja, praticamente se manteve comparado ao ano anterior.

O entrevistado-01 afirmou que foi o aumento no orçamento da assistência estudantil que permitiu um atendimento maior aos estudantes do campus. Ele informou que o aumento no orçamento não está atrelado ao número de matrículas no campus.

Porém, o entrevistado destacou que o orçamento para o campus Pesqueira tende a diminuir, não só pela redução no orçamento mas, também, por conta da última expansão da rede federal no Estado. Até 2015 o orçamento era rateado entre nove campi do IFPE. Com a terceira expansão do IFPE, em 2016, o orçamento passou a ser dividido para dezesseis campi. Em 2016 alguns programas tiveram perdas mínimas com relação aos auxílios financeiros ofertados no ano anterior. Já em 2017 e 2018, com a redução orçamentária da ação 2994 e com a distribuição deste orçamento para um número maior de campi, as ações e os programas desenvolvidos no campus Pesqueira e que fazem parte da política de assistência estudantil do IFPE passaram por mudanças e o alcance foi severamente reduzido.

O entrevistado-01 lembra que o orçamento gera a expectativa pelo pagamento das bolsas e auxílios, porque existe uma diferença entre o orçamento aprovado e o valor total desse orçamento a ser pago, o que ele chama de 'financeiro': 
Nós temos o orçamento, nós recebemos de Recife o orçamento, agora falta vir o financeiro, porque nós temos a expectativa de quanto iremos receber, mas não chegamos ainda a parte física, que recebemos, então sai primeiro o orçamento, que é a informação de: 'estamos descentralizando $X$ pra você '. Vocês têm isso de orçamento, trabalho em cima disso, pronto, e tendo isso eu faço uma folha de pagamento hoje, entrego e solicito a Recife, e Recife manda pro Campus que é o financeiro, que é o que vai cair na conta do estudante.

Portanto, pode acontecer dessa conta não fechar ou demorar a fechar, como relata o entrevistado-01: "Ano passado (2015) não conseguiu fechar, tanto é que só veio encerrar esse ano (2016), teve estudante que ainda em fevereiro estava recebendo visita técnica ou bolsa atleta ou bolsa permanência do ano passado".

No campus Pesqueira, de acordo com as informações obtidas nas entrevistas, o planejamento orçamentário é feito com base no ano anterior e depois de consultar alguns professores que participam de programas dentro da política de assistência ou utilizam as visitas técnicas no processo pedagógico. Para o entrevistado-06 essa forma de definir o orçamento não é a melhor. Para ele é um modelo que traz algumas complicações para a gestão, por isso ele sugeriu a implantação de um novo modelo. Esse modelo foi chamado por ele de 'conselho gestor do campus':

Com o conselho gestor do campus eleito e representado, eu acredito que vai favorecer essa discussão, porque o conselho gestor, você tem um representante docente, representante discente, representante administrativos, você tem os pais, você tem o estudante, você tem participantes da comunidade externa, então isso vai dar uma segurança maior para o gestor, de que o orçamento vai ser bem mais democraticamente distribuído, então provavelmente os professores de educação física vão ser chamados em algum momento lá no conselho gestor para dizer: 'olha, o que é que você acha que tem de demanda para o esporte?' Isso com o coordenador de esportes e vai ser chamado também o professor de artes: 'o que é que você tem de demanda para o programa de arte e cultura?' Vai ser chamado também o chefe do departamento de pesquisa, inovação e pós-graduação, 'o que é que você acha que tem de demanda para os programas de monitoria? O que é que você acha que tem de demanda para os programas do clube de astronomia'. Então isso vai ser feito, as demandas levantadas, e ai depois você distribui a fatia do bolo para cada programa, a gente sempre fez isso dialogando com os entes envolvidos, mas tomando uma decisão de equipe de gestão, e eu imagino que isso pode ser consolidado através do diálogo, através do conselho gestor do campus. (Entrevistado-06)

Durante as entrevistas sobre a definição do orçamento percebe-se que o Programa Bolsa Permanência - PBP - tem uma importância na política nacional de assistência estudantil desenvolvida nos campi do IFPE:

"No início do ano é planejado o nosso orçamento, nós fazemos um planejamento, levando em conta o que ocorreu no ano anterior e falamos com alguns professores, vemos a necessidade, o que eles querem, o que 
é que é necessário para a escola, visita técnica e tudo mais e daí é feito uma definição global, e depois ai sim, são feitos os ajustes, levando como prioridade o programa bolsa permanência e depois os outros programas." (entrevistado-01)

Após a definição do valor global, com todos os programas da política de assistência estudantil, o orçamento é apresentado à DAE/Reitoria, que pode aceitar ou propor ajustes. Se em 2016 os valores utilizados na assistência estudantil do campus Pesqueira permaneceram praticamente os mesmos de 2015, no ano de 2017 esse valor sofreu uma redução considerável. De acordo com os dados apresentados no resumo financeiro da assistência estudantil os recursos disponibilizados foram de $\mathrm{R} \$ 1.587 .587,79$. Uma redução de $11,1 \%$, comparado ao ano de 2016, que foi de $R \$ 1.785 .922,00$. Em 2018 o valor disponibilizado para o campus Pesqueira foi de $\mathrm{R} \$ 950.879,93$, uma redução de $46,8 \%$.

Alguns programas tiveram reduções no quantitativo de auxílios, outros aconteceram sem a oferta de auxílio financeiro, algumas visitas técnicas aconteceram com ajuda de custos reduzidas e outras medidas foram adotadas por conta da diminuição do orçamento.

De acordo com as planilhas financeiras apresentadas pela gestão do campus Pesqueira, com a redução do orçamento que se iniciou em 2017 alguns programas da política de assistência ao estudante passaram a ser executados com verbas que não eram da assistência estudantil. Em 2017, por exemplo, dos $\mathrm{R} \$ 1.587 .587,79$ definidos no orçamento para operar os programas, $\mathrm{R} \$ 390.971,95$ foram relocados de outro orçamento, como o de custeio.

\section{Considerações finais}

Todos os campi do IFPE têm autonomia para elaborar suas ações da assistência estudantil de acordo com suas necessidades institucionais e dos recursos orçamentários disponíveis. O campus Pesqueira desenvolve programas e ações que envolvem os estudantes de todos os níveis de ensino da instituição, com o objetivo de proporcionar condições econômicas, pedagógicas e psicológicas para a permanência do estudante.

A política de assistência estudantil do campus Pesqueira tem uma grande dimensão em termos de abrangência territorial, pois atende aos estudantes residentes de várias cidades vizinhas, tanto do Agreste, quanto do Sertão pernambucano.

A redução no orçamento da Ação 2994 afeta o potencial da política de assistência ao estudante e interfere em toda política de gestão do campus. Esse impacto pode ser ainda maior na modalidade do ensino médio integrado, pois boa parte dos estudantes do subsequente, do Proeja e superior já exercem alguma atividade remunerada ou prestam serviços de forma autônoma na região.

Com a redução do orçamento da assistência, iniciada em 2017, percebe-se que o campus Pesqueira priorizou o programa bolsa permanência. Os outros programas e ações tornaram-se dependentes deste, tendo a viabilidade, a forma e o tempo definidos 
de acordo com os valores disponíveis após execução do PBP. Diante disso, o estudante, por falta de um auxílio financeiro, passa a ter dificuldade de participar de ações e programas, muitas vezes no contra turno de aula, que contribuem para a sua formação integral.

\section{Referências}

BRASIL. Decreto n. 7.234, de 19 de julho de 2010: dispõe sobre o Programa Nacional de Assistência Estudantil - Pnaes. Brasília: Presidência da República, 2010.

BRASIL. Lei n. 11.892, de 29 de dezembro de 2008. Institui a rede federal de educação profissional, científica e tecnológica, cria os institutos federais de educação, ciência e tecnologia e dá outras providências. Brasília: Presidência da República, 2008.

BRASIL. Plano de desenvolvimento institucional do Instituto Federal de Pernambuco 2014-2018. Recife: IFPE, 2015. Disponível em http://www.ifpe.edu.br/acesso-ainformacao/institucional/pdi-1/pdi-completo-2014-2018.pdf. Acesso em 20 ago. 2015.

BRASIL. Política nacional de assistência social: PNAS 2004. Brasília: Presidência da República, 2005.

COSTA, Simone Gomes. A equidade da educação superior: uma análise das políticas de assistência estudantil. Porto Alegre: Ufrgs, 2010. 203f. Dissertação (Mestrado em Sociologia) - Universidade Federal do Rio Grande do Sul.

FONAPRACE. Revista comemorativa 25 anos: histórias, memórias e múltiplos olhares. Brasília: Andifes, 2012.

GIL, Antônio Carlos. Como elaborar projetos de pesquisa. São Paulo: Atlas, 2002.

GOMES, Fernanda Cunha. O programa nacional de assistência estudantil (Pnaes) no âmbito dos institutos federais de educação, ciência e tecnologia: a necessária interpretação sistemática da Constituição Federal, das leis n. 11.892/2008 e n. 9.394/1996 e do decreto n. 7.234/2010. Brasília: Conteúdo Jurídico, 2011. Disponível em http://jus.com.br/artigos/19894/o-programa-nacional-de-assistencia-estudantil-pnaes-noambito-dos-institutos-federais-de-educacao-ciencia-e-tecnologia\#ixzz3VWaSsQpu. Acesso em 18 maio 2015.

IFPE. Histórico institucional. Disponível em http://reitoria.ifpe.edu.br/institucional/index.jsf?page=Hist\%25C3\%25B3rico\&campi=Reitori a. Acesso em 18 jun. 2020.

IFPE. Relatório integrado de gestão do IFPE - 2018. Disponível em https://portal.ifpe.edu.br/o-ifpe/desenvolvimento-institucional/relatorios-de-gestao. Acesso em 3 de jun. 2020.

IFPE. Proposta da política de assistência estudantil do IFPE. Recife: IFPE, 2012.

MINAYO, Maria Cecília de Souza. O desafio do conhecimento: pesquisa qualitativa em saúde. São Paulo/Rio de Janeiro: Hucitec/Abrasco, 1998.

OLIVEIRA, Dalila Andrade. Análise de Conteúdo Temático-Categorial: Uma proposta de sistematização. Rev. Enferm. UERJ, Rio de Janeiro, v. 16, n. 4, 2008, p. 569-76.

OLIVEIRA, Dalila Andrade. Política educacional. In: OLIVEIRA, Dalila Andrade; DUARTE, Adriana Cancella; VIEIRA, Lívia Fraga. Dicionário: trabalho, profissão e condição docente. Belo Horizonte: UFMG, 2010. 
TAUFICK, Ana Luiza de Oliveira Lima. Análise da política de assistência estudantil dos institutos federais de educação, ciência e tecnologia. Revista Brasileira de Política e Administração da Educação. Goiânia, v. 30, n. 1, 2014, p. 181-201.

TROTTA, Wellington. Política social: perspectiva de medidas efetivamente públicas. Achegas.net, Rio de Janeiro, n. 43, 2010, p. 81-99.

VERGARA, Sylvia Constant. Projetos e relatórios de pesquisa em administração. São Paulo: Atlas, 1998.

Carlos Eduardo Correia Silva é professor no Instituto Federal de Educação, Ciência e Tecnologia de Pernambuco.

Orcid: https://orcid.org/0000-0003-2148-5943.

Endereço: Coordenação de Esporte do IFPE - campus Pesqueira - BR 232 KM 208 Loteamento Portal, Prado - 55200-000 - Pesqueira - PE -Brasil.

E-mail: cecdasilva.cc@gmail.com.

Katharine Ninive Pinto Silva é professora no Programa de Pós-Graduação em Educação da Universidade Federal de Pernambuco.

Orcid: https://orcid.org/0000-0002-7293-4289.

Endereço: Secretaria do Programa de Pós-Graduação em Educação, Centro de Educação, campus universitário - 50670-901- Pesqueira - PE -Brasil.

E-mail: katharineninive@gmail.com.

Recebido em 31 de julho de 2020.

Aceito em 18 de março de 2021.

cc) (1) $(9)$ 